\title{
Breast feeding in Israel: maternal factors associated with choice and duration
}

\author{
Pnina Ever-Hadani, Daniel S Seidman, Orly Manor, Susan Harlap
}

\begin{abstract}
Study objectives - To determine the influence of maternal characteristics on the incidence and duration of breast feeding.

Design - All the women who delivered in three obstetric wards within a two year period were surveyed. These three wards cover $93 \%$ of all births in the Jerusalem district. Women were interviewed on breast feeding of the previous child on the first or second day post partum by a research nurse.
\end{abstract}

Participants - Altogether 8486 women whose previous pregnancy had resulted in a live born singleton who survived for at least one year.

Measurements and main results Breast feeding information was linked to demographic and health information from hospital records. Using logistic regression analysis, failure to start breast feeding was best predicted $(p<0.001)$ by caesarean delivery, infant's birth weight, maternal smoking habits, and mother being non-immigrant. Maternal age ( $<24$ or $>40$ years) and father being an ultraorthodox Jew were also positively $(p<0.05)$ associated with the decision to breast feed. Long term breast feeding (three months or more) was strongly affected $(p<0.001)$ by maternal education level, with both women with the fewest and the greatest number of years of schooling more likely to breast feed. A similar association was observed in all ethnic groups. Primipara and grandmultipara (parity $>4$ ), new immigrants, ultraorthodox Jews, and non-smokers breast fed their babies for longer.

Conclusions - The importance of maternal characteristics in relation to breast feeding was shown. Caesarian delivery and the infant's birth weight were strongly related to the decision to breast feed as were the demographic characteristics of mother's age and her country of birth. Education was not related to this decision but was strongly associated with the duration of breast feeding, as was parity. The behavioural characteristics of smoking and being ultraorthodox were related to both the decision to start and the duration of breast feeding. Efforts to encourage breast feeding ought to be targeted during the hospital stay and post partum period towards women identified as being at increased risk.

( E Epidemiol Community Health 1994;48:281-285
The growing public and professional recognition of the benefits of breast feeding have led to concern about unsuccessful breast feeding and its early termination. Intervention programmes have been promoted to encourage breast feeding. ${ }^{1-3}$ The efficiency of measures designed to maintain breast feeding for longer depends on identifying mothers at particular risk. Those women who are more likely to elect to formula feed their babies have been shown in developed countries to be characterised by low income, ${ }^{4-7}$ limited number of years of schooling, ${ }^{8-10}$ young age, ${ }^{9-12}$ previous children, ${ }^{11-12}$ out of wedlock births, ${ }^{5-11}$ work outside home, ${ }^{13}$ and belonging to socioeconomically disadvantaged ethnic groups. ${ }^{4-8} 11$ 13-15

Only a few studies ${ }^{1} 8$ have attempted to control simultaneously for the confounding effects of various maternal demographic factors such as age, parity, or social class, which are highly correlated with the level of formal education and ethnic origin. Furthermore, most investigations obtained the data through telephone and postal surveys rather than by direct interview with the mother. ${ }^{711} 16$ Other studies have been less affected by selection bias, but were either small in size $e^{1013}$ or limited to a single maternity ward. ${ }^{11}$

The Jerusalem population is very heterogeneous with a wide diversity of socioethnic groups. We investigated data, obtained by interviews post partum, over a two year period from the entire paturient population of Jerusalem.

The purpose of this study was to examine factors influencing the likelihood of choosing to breast feed and persisting for at least three months. We evaluated the independent effect of maternal characteristics on duration of breast feeding, using a multiple regression analysis technique to adjust for the influence of possible confounding variables.

\section{Methods}

SAMPLE

As part of the Jerusalem Perinatal Study, 93\% of all the Jewish women who delivered between November 1974 and December 1976 in the Jerusalem district were interviewed on the first or second post partum day by a research nurse. Data from the interviews, including information about breast feeding of the previous child were recorded and linked to demographic and health information derived independently from hospital records and birth certificates.

The interviews included questions on health insurance, private obstetric care, previous illnesses, menstruation, threatened abortion and hormone treatment, birth control methods 
used since any previous pregnancy, and duration of breast feeding after the previous birth.

The data were made available from the Jerusalem Study on Oral Contraceptive Use, ${ }^{17}$ one of the interlocking epidemiological studies making up the Jerusalem Perinatal Study. ${ }^{17} 18$

The study group included 8486 of the interviewed women, whose last pregnancy had resulted in a live born singleton who survived for at least one year. The women were all specifically questioned about the duration of breast feeding after their previous birth.

Data obtained by questioning the mother may be subject to recall bias. ${ }^{19}$ The validity of mothers' reporting their breast feeding history more than 20 years after their children's birth has been studied in the Jerusalem population. ${ }^{20}$ It was concluded that interview with mothers about their breast feeding practices seems to be valid for widely different educational and cultural groupings in the Jewish population in Israel.

\section{VARIABLES}

The dependent variable breast feeding duration, was dichotomised into prematernity leave, leave of three months or less, and post maternity leave, leave of more than three months. This division follows from the three months' paid maternity leave in Israel. A separate analysis was undertaken examining the decision to initiate breast feeding, as the dependent variable. No distinction was made between full and partial breast feeding.

The independent variables included maternal age at delivery; birth order; maternal education (measured by the number of years of schooling and classified into five categories according to the classification used by the Israeli Bureau of Statistics); social class (determined by the level of municipal taxes levied to the mother's residential neighbourhood and classified into three categories ${ }^{17}$ ); ethnicity (determined by the country of birth of the respondent: for those born in Israel the country of birth of their mother was used); and birth weight, as well as the following variables which were used dichotomously: father is Yeshiva student (rabbinical seminar); mother being a house wife, maternal smoking, Israeli born, and caesarean section.

\section{DATA ANALYSIS}

Logistic regression controlling for sociodemographic variables ${ }^{21}$ was used to estimate the odds ratios for initiating breast feeding and for breast feeding after the end of maternity leave for those who breast fed. In addition, interaction effects were sought between maternal education and ethnic origin (Asia, North Africa, or Europe/America). The duration of breast feeding was evaluated using a stepwise multiple regression technique adjusting for the effects of confounding factors in a linear additive model. ${ }^{22} \mathrm{~A}$ second order polynomial model (in education) was fitted. Statistical significance was determined using the $\mathrm{F}$ test, with significance defined as $p<0.05$.

\section{Results}

STUDY POPULATION

The study population was relatively young $(80 \%$ under 30 years of age) and half of the women had been born in Israel. Forty one per cent of the women had had a high school education (eight to 12 years of schooling) and an additional $34 \%$ had had more than 12 years of formal education. Thirty three per cent were primipara and $19 \%$ grandmultipara (five children or more). Sixty per cent of the women worked outside the home and $14 \%$ smoked. Almost half $(46 \%)$ of the women belonged to the middle or higher social class and $22 \%$ belonged to the ultraorthodox Jewish community of Jerusalem, as their husbands were Yeshiva students or teachers.

\section{INITIATION OF BREAST FEEDING}

Altogether $79.3 \%$ started to breast feed. Women aged 24 years or younger and those aged 40 years or more were most likely to choose to breast feed $(p<0.05)$, but the number of elder parturients was relatively small. Birth order, maternal education, social class, age at marriage, and work outside the home did not significantly influence the decision to begin breast feeding (table 1). This may partly reflect the overall high incidence of breast feeding.

Mothers married to Yeshiva students $(\mathrm{p}<0.01)$ or born outside Israel $(\mathrm{p}<0.001)$ were significantly more likely to breast feed. Maternal smoking had a significant negative $(p<0.001)$ effect on breast feeding. Low birth weight of the infant $(<2500 \mathrm{~g})$ and delivery by caesarean section were also significantly associated with a tendency to formula feed.

\section{DURATION OF BREAST FEEDING}

While $36.8 \%$ of all the women studied breast fed for longer than three months, $46.5 \%$ of those who started continued for at least three months. Primipara and grandmultipara were significantly $(\mathrm{p}<0.001)$ more likely to breast feed for three months or more (table 2). Mothers married to Yeshiva students $(\mathrm{p}<0.001)$ and those with infants weighing 3500 to $4000 \mathrm{~g}$ at birth $(\mathrm{p}<0.002)$ were found to prolong the breast feeding period significantly.

Factors of maternal smoking and mothers born in Israel were observed to be associated significantly with a negative $(p<0.001)$ effect on long term breast feeding.

The mother's formal education was significantly related to breast feeding for longer than the period of maternity leave. Mothers with the fewest years of schooling on the one hand, and those with the highest level education on the other, were most likely to breast feed for extended periods.

Examination of the duration of breast feeding as a continuous variable showed that the education level had a strong effect on the duration of breast feeding regardless of the mother's ethnic origin (figure).

\section{Discussion}

The present large study population provided 
Table 1 Incidence and adjusted odds ratios of breast feeding in relation to maternal and obstetrical characteristics.

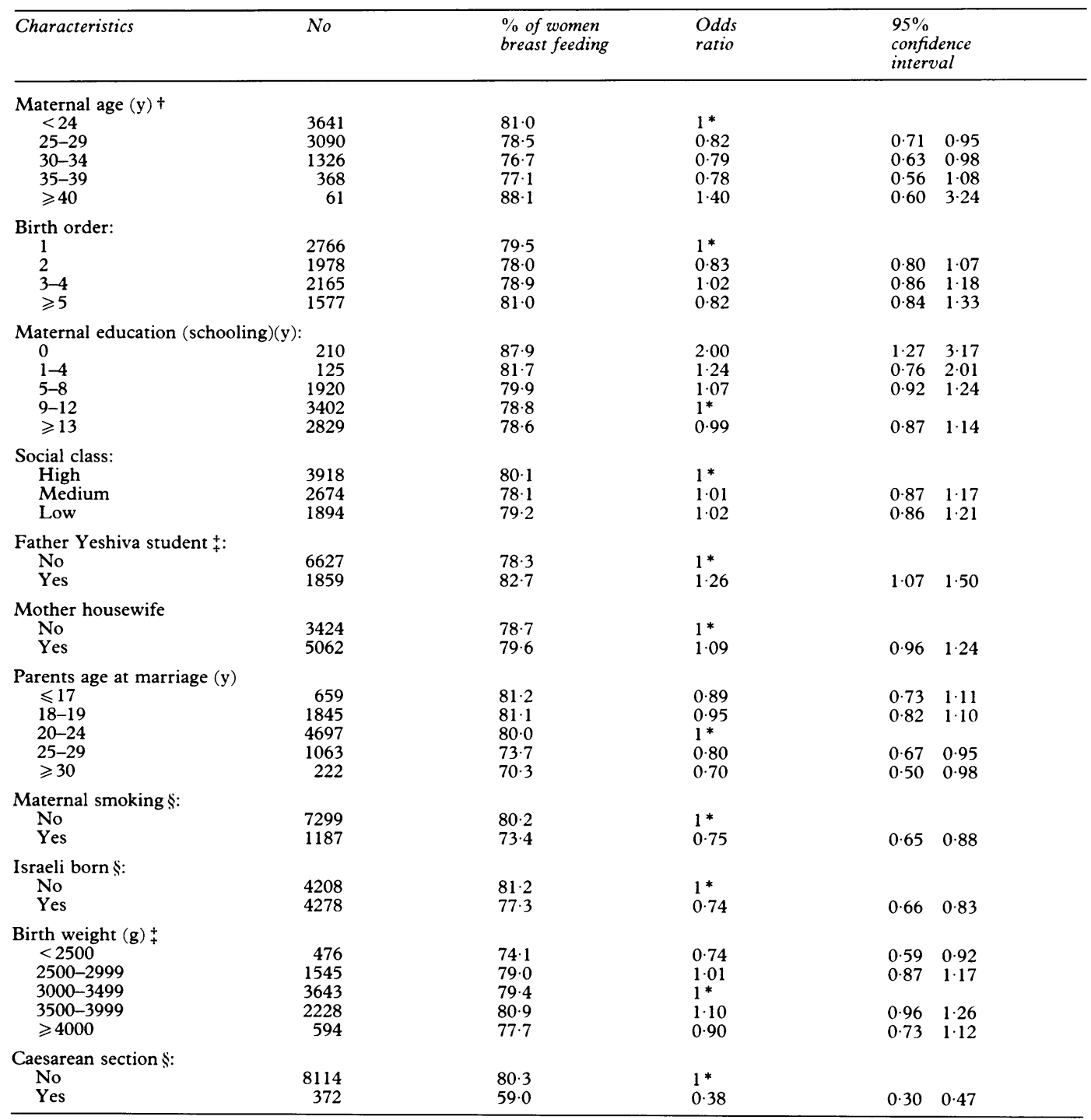

* Reference group for adjusted odds ratios derived from logistic regression analysis.

Variable statistically significant at $+p<0.05,+p<0.01$, and $\$ p<0.001$.

an opportunity for an extensive evaluation of the independent effect on breast feeding of several maternal factors. Although most women $(80 \%)$ were breast feeding on discharge from hospital, a number of variables was associated with failure to initiate breast feeding. As previously described ${ }^{1123}$ caesarean section was found to discourage breast feeding. Low birth weight infants were also less likely to be breast fed. More support should therefore be targeted to women who have a low birth weight baby, or are delivered by caesarean section during the critical time in hospital when breast feeding is being established.

Socioeconomic background may also be an important factor influencing breast feeding decisions during the hospital stay, since women who were born in Israel and those who smoked had a significantly lower rate of early lactation.

The importance of maternal characteristics in relation to the duration of breast feeding has been shown in the present study. In agreement with previous reports, ${ }^{8} 101216$ maternal age, parity, education, and ethnic origin were significantly associated with a duration of breast feeding of over three months.
The educational level of the mother and her ethnicity have been previously found to be the two most important independent factors that influence the decision to breast feed. ${ }^{816}$ However, the interaction between these factors may differ in various populations. The incidence of breast feeding seemed to be more related to maternal education and less dependent on ethnicity. ${ }^{81216}$ This relationship was confirmed by the present data. However, a positive linear association between education level and breast feeding duration, as previously shown, ${ }^{81216}$ was not found.

In contrast, in our study, mothers with little education breast fed for a longer mean duration than mothers with a high school education. Nevertheless, women tended to breast feed for longer as their educational attainments increased beyond 12 years of schooling. This observation produced a truncated ' $U$ '-shaped or an ' $S$ '-shaped curve - a pattern that has been described previously by Rassin et al. ${ }^{4} \mathrm{It}$ may be attributed to the tendency of less educated mothers to cling to traditional practices on one hand, and the predilection of more educated women to adopt modern western 
Table 2 Incidence and adjusted odds ratios of breast feeding for three months or more in relation to maternal and obstetrical characteristics, only for those who initiated breast feeding.

\begin{tabular}{|c|c|c|c|c|c|}
\hline \multirow[b]{2}{*}{$\begin{array}{c}\text { Maternal age }(y) \\
\leqslant 24 \\
25-29 \\
30-34 \\
35-39 \\
\geqslant 40\end{array}$} & \multirow{2}{*}{\begin{tabular}{r|} 
No \\
\\
3112 \\
2569 \\
1087 \\
306 \\
58
\end{tabular}} & \multirow{2}{*}{$\begin{array}{l}\% \text { breast feeding } \\
\text { for } \\
\geqslant 3 \text { months } \\
42 \cdot 8 \\
47 \cdot 1 \\
50 \cdot 1 \\
59 \cdot 2 \\
67 \cdot 2\end{array}$} & \multirow{2}{*}{$\begin{array}{l}\text { Odds } \\
\text { ratio } \\
\\
1^{*} \\
1 \cdot 07 \\
1 \cdot 22 \\
1.52 \\
2 \cdot 08\end{array}$} & \multicolumn{2}{|c|}{$\begin{array}{l}95 \% \\
\text { confidence } \\
\text { interval }\end{array}$} \\
\hline & & & & $\begin{array}{l}0.93 \\
1.00 \\
1.12 \\
1.11\end{array}$ & $\begin{array}{l}1.23 \\
1.51 \\
2.08 \\
3.89\end{array}$ \\
\hline $\begin{array}{l}\text { Birth order } \S \\
1 \\
2 \\
3-4 \\
\geqslant 5+\end{array}$ & $\begin{array}{l}2312 \\
1611 \\
1819 \\
1390\end{array}$ & $\begin{array}{l}45 \cdot 5 \\
42 \cdot 0 \\
45 \cdot 6 \\
54 \cdot 5\end{array}$ & $\begin{array}{l}1 * \\
0 \cdot 80 \\
0 \cdot 83 \\
1 \cdot 01\end{array}$ & $\begin{array}{l}0.70 \\
0.72 \\
0.82\end{array}$ & $\begin{array}{l}0.92 \\
0.97 \\
1.25\end{array}$ \\
\hline $\begin{array}{l}\text { Maternal educat } \\
0 \\
1-4 \\
5-8 \\
9-12 \\
13+\end{array}$ & $\begin{array}{r}204 \\
107 \\
1611 \\
2904 \\
2306\end{array}$ & $\begin{array}{l}63 \cdot 2 \\
54 \cdot 2 \\
42 \cdot 6 \\
42 \cdot 6 \\
52 \cdot 2\end{array}$ & $\begin{array}{l}1.32 \\
0.99 \\
0.88 \\
1^{*} \\
1.44\end{array}$ & $\begin{array}{l}0.95 \\
0.65 \\
0.77 \\
1.27\end{array}$ & $\begin{array}{l}1.84 \\
1.50 \\
1.01 \\
1.64\end{array}$ \\
\hline $\begin{array}{l}\text { Social class: } \\
\text { High } \\
\text { Medium } \\
\text { Low }\end{array}$ & $\begin{array}{l}3325 \\
2200 \\
1607\end{array}$ & $\begin{array}{l}50 \cdot 9 \\
40 \cdot 6 \\
45 \cdot 2\end{array}$ & $\begin{array}{l}1^{*} \\
0.90 \\
0.98\end{array}$ & $\begin{array}{l}0.78 \\
0.83\end{array}$ & $\begin{array}{l}1.03 \\
1 \cdot 14\end{array}$ \\
\hline $\begin{array}{l}\text { Father Yeshiva s } \\
\text { No } \\
\text { Yes }\end{array}$ & $\begin{array}{l}5487 \\
1645\end{array}$ & $\begin{array}{l}43 \cdot 8 \\
55 \cdot 3\end{array}$ & $\begin{array}{l}1^{*} \\
1.61\end{array}$ & 1.39 & $1 \cdot 88$ \\
\hline $\begin{array}{l}\text { Mother housewi } \\
\text { No } \\
\text { Yes }\end{array}$ & $\begin{array}{l}2830 \\
4302\end{array}$ & $\begin{array}{l}46 \cdot 1 \\
46 \cdot 8\end{array}$ & $\begin{array}{l}1^{*} \\
0.95\end{array}$ & $0 \cdot 85$ & 1.07 \\
\hline $\begin{array}{l}\text { Parent's age at n } \\
\quad \leqslant 17 \\
18-19 \\
20-24 \\
25-29 \\
\geqslant 30\end{array}$ & $\begin{array}{r}578 \\
1604 \\
3972 \\
815 \\
163\end{array}$ & $\begin{array}{l}48 \cdot 9 \\
46 \cdot 4 \\
45 \cdot 2 \\
49 \cdot 2 \\
54 \cdot 0\end{array}$ & $\begin{array}{l}1.21 \\
1.10 \\
1 * \\
1.08 \\
1.26\end{array}$ & $\begin{array}{l}1.00 \\
0.96 \\
\\
0.91 \\
0.88\end{array}$ & $\begin{array}{l}1.47 \\
1.25 \\
1.29 \\
1.80\end{array}$ \\
\hline $\begin{array}{l}\text { Maternal smokin } \\
\text { No } \\
\text { Yes }\end{array}$ & $\begin{array}{r}6196 \\
920\end{array}$ & $\begin{array}{l}48 \cdot 6 \\
32 \cdot 6\end{array}$ & $\begin{array}{l}1^{*} \\
0.63\end{array}$ & 0.54 & 0.73 \\
\hline $\begin{array}{l}\text { Israeli born } §: \\
\text { No } \\
\text { Yes }\end{array}$ & $\begin{array}{l}3663 \\
3469\end{array}$ & $\begin{array}{l}51 \cdot 5 \\
41 \cdot 1\end{array}$ & $\begin{array}{l}1^{*} \\
0.61\end{array}$ & 0.55 & 0.68 \\
\hline $\begin{array}{l}\text { Birth weight (g) } \\
\quad \leqslant 2500 \\
2500-2999 \\
3000-3499 \\
3500-3999 \\
\geqslant 4000\end{array}$ & $\begin{array}{r}383 \\
1296 \\
3050 \\
1903 \\
482\end{array}$ & $\begin{array}{l}45 \cdot 4 \\
43 \cdot 9 \\
45 \cdot 2 \\
50 \cdot 2 \\
46 \cdot 9\end{array}$ & $\begin{array}{l}1 \cdot 10 \\
0.93 \\
1 * \\
1 \cdot 22 \\
0.98\end{array}$ & $\begin{array}{l}0.88 \\
0.81 \\
\\
1.09 \\
0.80\end{array}$ & $\begin{array}{l}1.38 \\
1.06 \\
1.38 \\
1.20\end{array}$ \\
\hline $\begin{array}{l}\text { Caesarean sectio } \\
\text { No } \\
\text { Yes }\end{array}$ & $\begin{array}{r}6659 \\
227\end{array}$ & $\begin{array}{l}46 \cdot 5 \\
45 \cdot 5\end{array}$ & $\begin{array}{l}1^{*} \\
0.96\end{array}$ & 0.73 & $1 \cdot 27$ \\
\hline
\end{tabular}

* Reference group for adjusted odds ratios derived from logistic regression analysis

Variable statistically significant at $+p<0.05, \pm p<0.01 ; \S<0.001$

trends encouraging lactation on the other hand. ${ }^{1516}$

The influence of maternal education on the duration of breast feeding was independent of other maternal characteristics such as age, parity, social class, and work outside the home. Maternal education level remains a major indication of the need for direct nutrition advice. ${ }^{27}$

Maternal work outside home did not correlate with breast feeding duration. This unexpected observation has nevertheless been reported previously. ${ }^{25}$ Social class, determined by parental occupation, ${ }^{17}$ and maternal age at marriage, did not influence breast feeding duration. However, other sociocultural traits, such as maternal smoking and belonging to the ultraorthodox Jewish community, did affect the incidence of breast feeding. This may reflect the importance of family psychosocial support to breast feeding success. ${ }^{24}$.

The present study provides an analysis of the determinants of breast feeding initiation and duration in Jerusalem women. The data collection for this study resulted in a good coverage of the target population and most of the mothers' relevant characteristics were included in the data. However, no information was available about the exclusiveness of breast feeding. Although the data were collected during the $1970 \mathrm{~s}$, the relevance of the study has not diminished since it improves our understanding of the interaction of maternal characteristics with breast feeding in the light of the continuing importance of promoting breast feeding. ${ }^{26}$

The effectiveness of intervention programmes designed to promote breast feeding ${ }^{23}$ depends on the ability to identify mothers at high risk of stopping breast feeding early. The present data about breast feeding in Jerusalem allowed us to test, by applying a multivariate statistical technique, the independent predictive power of maternal and obstetric factors. Different variables were characteristic of women identified as being at risk for either failing to start breast feeding during the hospital stay or breast feeding for only a short time. Advice from health professionals at the 


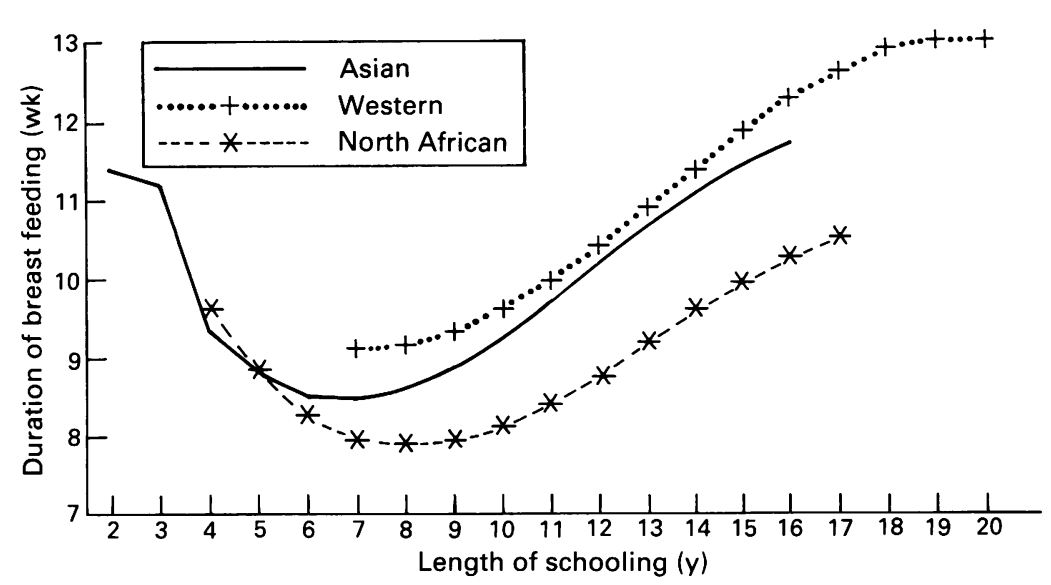

Duration of breast feeding adjusted for maternal age, birth order, social class, profession, age at marriage, smoking, birth weight and caesarean section using a multiple regression analysis by maternal education and ethnic origin.

maternity ward should be guided towards women who give birth by caesarean section and to mothers of low birth weight babies. Breast feeding promotion programmes in the first weeks postpartum may be of greatest benefit to young women with fewer than 12 years of schooling and who smoke.

1 American Academy of Pediatrics, policy statement based on task force. The promotion of breast feeding. Pediatrics task force. The

2 Palti H, Valderama C, Pogrund R, Jarkoni J, Kurtzman C. Evaluation of the effectiveness of a structured breast feeding promotion program integrated into a maternal and child health service in Jerusalem. Isr $\mathcal{f}$ Med Sci 1988;24:342-8.

3 Sannder SE, Caroll J. Post-partum breast feeding support: Impact on duration. $\mathcal{f}$ Am Diet Assoc 1988;88:213-15.

4 Rassin DK, Richardson J, Baranowski T, Nader PR Guenther N, Bee DE, Brown JP. Incidence of breas feeding in a low socioeconomic group of mothers in the United States: Ethnic patterns. Pediatrics 1984;73:132-7.

5 Branowski T, Bee DE, Rassin DK, Richardson CI, Brown JP, Guenther N, Nader PR. Social support, social influence, ethnicity and the

6 Mansbach IK, Palti H, Pevsner B, Pridan H, Palti Z. Advice from the obstetrician and other sources: Do they effect women's breast feeding practices? A study among different Jewish groups in Jerusalem. Soc Sci Med 1984;19:157-62.

7 Andrew EM, Clancy KL, Katz MG. Infant feeding practices of families belonging to a prepaid group practice health care plan. Pediatrics 1980;65:978-88.

8 Karinij N, Shiono PH, Rhoads GG. Breast-feeding incidence and duration in black and white women. Pediatrics 1988;81:365-71.

9 Mohrer J. Breast and bottle feeding in an inner city community: An assessment of perceptions and practices. Med Anthropol 1979;31:125-45.

10 Wright HJ, Walker PC. Prediction of duration of breast feeding in primiparas. $\mathcal{F}$ Epidemiol Community Health feeding in primip

11 Samuels SE, Margen S, Schoen EJ. Incidence and duration of breast feeding in a health maintenance organization population. Am f Clin Nutr 1985;44:504-10.

12 Forman MR, Fetterly K, Graubard BI, Wooton KG. Exclusive breast feeding of newborns among married women in the United States: the National Natality Surveys of 1969 and 1980. Am f Clin Nutr 1985;42:864-9.

13 Scrimshaw SCM, Engle PL, Arnold L, Haynes K. Factors affecting breast feeding among women of Mexican origin or descent in Los Angeles. Am $f$ Public Health 1987;77:467-70.

14 Smith JC, Mhango CG, Warren CW, Rochat RW, Huffman SL. Trends in the incidence of breast feeding for hispanics of Mexican origin and Anglos in the USMexico border. Am f Public Health 1982;72:59-61.

15 Goel KM, House F, Shanks RA. Infant-feeding practices among immigrants in Glasgow. $B M \mathcal{T} 1978 ; 2: 1181-3$.

16 Eckhardt $\mathrm{KW}$, Henershot GE. Analysis of the reversal in breast feeding trends in the early 1970s. Public Health Rep breast feeding trenc

17 Harlap S, Davies AM. The pill and births: The ferusalem Study. Bethesda, MD: National Institute of Child Health and Human Development, 1978 .

18 Harlap S, Davies AM, Grover NB, Prywes R. The Jerusalem Perinatal Study: The first decade 1964-1973. Isr f Med Sci 1977;13:1073-91.

19 Siedman DS, Slater PE. Accuracy of the medical interview. Br 7 Obstet Gynaecol 1987;94:721-3.

20 Kark JD, Troya G, Friedlander Y, Slater PE, Stein Y. Validity of maternal reporting of Breast Feeding history and the association with blood lipids in 17 year olds in and the association with opidemiol Community Health 1984;38: Jerusalem.

21 Dixon WJ, Brown MB, Engelman L, et al. BMPD statistical software 1981 . Berkeley California, University of California Press, 1981.

22 Nie NH, Jenkins CH, Steinbrenner K, Bent DH. Statistical Package for the Social Sciences. New York: McGraw Hill Inc. 1975.

23 Procianoy RS, Fernandes-Filho PH, Lazaro L, Sartori NC. Factors affecting breast feeding: The influence of caesarean section. 7 Trop Pediatr 1984;30:39-42.

24 Ekwo EE, Dusdieker L, Booth B, Seals B. Pychosocial factors influencing the duration of breast feeding by primigravidas. Acta Paediatr Scand 1984;73:241-7.

25 Loughlin HH, Clapp-Channing NE, Gehlbach SH, Pollard JC, McCutchen TM. Early termination of breast feeding: identifying those at risk. Pediatrics 1985;75:508-13.

26 Cunningham AS, Jelliffe DB, Jelliffe EFP. Breast-feeding and health in the 1980s: A global epidemiologic review. Pediatrics 1991;118:659-66. 